\title{
Benutzung 2017
}

\begin{tabular}{|l|r|r|r|r|}
\hline Allgemeine Angaben zur Benutzung & \multicolumn{2}{|c|}{2016} & \multicolumn{2}{|c|}{2017} \\
\hline Aktive Benutzer & 28.304 & $-4,3 \%$ & 26.532 & $-6,3 \%$ \\
Neue Bibliotheksausweise & 9.426 & $-7,2 \%$ & 8.934 & $-5,2 \%$ \\
Öffnungstage & 293 & & 289 & \\
Entleihungen & 1.539 .989 & $+0,1 \%$ & 1.475 .582 & $-4,1 \%$ \\
Verlängerungen & 995.245 & $+0,7 \%$ & 969.223 & $-2,6 \%$ \\
Information & & & & \\
Auskunftsanfragen & 24.984 & $-3,8 \%$ & 21.275 & $-14,8 \%$ \\
davon virtuelle Auskunft & 1.967 & $-2,8 \%$ & 1.872 & $-4,8 \%$ \\
Fernleihe & & & & \\
Aktiv & 81.016 & $-6,3 \%$ & 76.038 & $-6,1 \%$ \\
Passiv & 19.164 & $+0,2 \%$ & 18.538 & $-3,2 \%$ \\
Lesesäle & & & & \\
Hauptlesesaal & 205.339 & $-8,2 \%$ & 258.492 & $+25,8 \%$ \\
Fachlesesäle & 9.019 & $+22,3 \%$ & 10.862 & $+20,4 \%$ \\
\hline
\end{tabular}

Die klassischen Benutzungsbereiche haben 2017 eine erfreuliche Bilanz aufzuweisen. Trotz teilweise massiver Lärm- und Geruchsbelastungen sowie der schwierigen Zugangs- und Parksituation durch die Errichtung des Erweiterungsbaus sind die meisten Benutzerinnen und Benutzer der Bibliothek treu geblieben. Hervorzuheben ist der außerordentliche Anstieg bei der Nutzung der Lesesäle. Der Hauptlesesaal und der Sonderlesesaal werden für die konzentrierte Arbeitsatmosphäre sehr geschätzt. Das bestätigt die von Dezember 2017 bis Januar 2018 durchgeführte Lesesaalumfrage. Welche weiteren Erkenntnisse diese Benutzerumfrage erbracht hat, lesen Sie im nächsten WLBforum, da die Auswertung zum Redaktionsschluss noch nicht abgeschlossen war. Im Hinblick auf die Nutzung elektronischer Angebote ist es noch nicht gelungen, konsistente Kennzahlen zu entwickeln; Plattformen der Anbieter, e-Pakete und Zählweisen ändern sich, die Aussagekraft ist dadurch reduziert.

Dennoch sind einige absolute Zahlen von Interesse, wie z. B. die OPAC-Zugriffe im Jahr 2017: 1.726.872. Das sind 4.731 pro Tag, 197 in der Stunde, 3 in der Minute. Oder die Anzahl der Zugriffe auf unsere Digitalen Sammlungen, die auf 9.718 Titel angewachsen ist: 602.791 , das sind 1.651 weltweite Klicks pro Tag, 68 pro Stunde.

Ein wachsendes Angebot elektronischer Ressourcen mit Fernzugriff macht den Gang in die Bibliothek in vielen Fällen und mit zunehmender Tendenz überflüssig. Diejenigen, die mit dem Bestand arbeiten, sei es mit dem Präsenz- oder mit dem historischen Bestand, werden weiterhin den Weg in die Bibliothek suchen, ebenso wie diejenigen, die ein analoges Buch einer digitalen Version vorziehen oder diejenigen, die sich in der Lernumgebung wohl fühlen und den Kommunikationsort Bibliothek aufsuchen möchten.

Letzteres nimmt an Bedeutung zu. Geht man mit offenen Augen durch das Haus, ist das Bild geprägt von jungen Leuten, die gemeinsam in Gruppen oder mit großen Stapeln Lehrbücher lernen. Die Grafik zeigt es:

Die Gruppe der Studierenden, Schülerinnen/ Schüler und sonstigen Auszubildenden macht $3 / 4$ der Benutzerschaft aus. Die Bibliothek richtet deshalb ihren

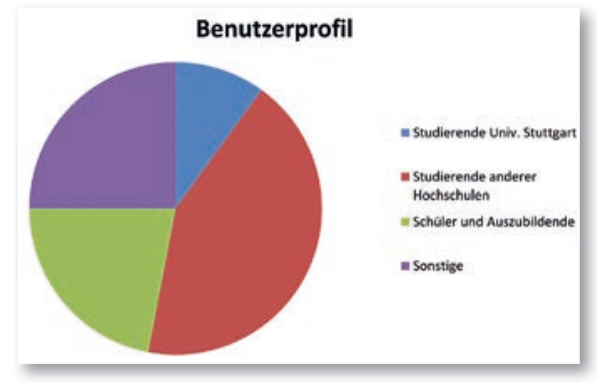
Service mit entsprechenden Literatur- und Schulungsangeboten in erster Linie an dieser Benutzergruppe aus. Wesentlich ist, dass die Bibliothek finanziell so ausgestattet wird, dass wissenschaftliche Publikationen, analog und digital, schnell und effizient zur Verfügung gestellt werden können. Hervorragende wissenschaftliche und wirtschaftliche Ergebnisse erfordern eine ebensolche Informationsinfrastruktur. Ohne solide Basis können keine Leuchttürme entstehen. Diese sicherzustellen, ist Aufgabe der Politik.

Martina Lüll 